\title{
Apresentação. Reviravoltas do simbólico no BRASIL CONTEMPORÂNEO
}

\author{
Lidiane Soares RODRIGUES* \\ Rodrigo Constante MARTINS**
}

As reviravoltas da hierarquia simbólica que resultaram das presidências petistas ainda não se tornaram objeto de estudo sistemático por parte da sociologia da cultura brasileira. A proposta deste dossiê considera imperativo o estabelecimento desta agenda de pesquisa. Sobretudo, no conjunto, o que está em jogo, embora ainda não tenha sido tematizado nestes termos, e tampouco rotinizado, são os efeitos, para a cultura política e para o campo simbólico, da chegada à Presidência da República do único partido de massas no Brasil, situado historicamente à esquerda - o Partido dos Trabalhadores (PT) (RODRIGUES, 2018).

Se a gênese destas reviravoltas não se encerra no período compreendido entre 2002 e 2016, seus desdobramentos também não parecem ser conjunturais. Portanto, é necessário o alargamento do escopo no tempo e a articulação de filões temáticos que têm dialogado cada vez menos: sociologia do gosto e estilo de vida, sociologia da educação, sociologia da arte e da indústria cultural, sociologia política. Da integração destas abordagens depende a possibilidade de ultrapassar as constatações difusas e divagantes a respeito de fenômenos aos quais não poderíamos passar incólumes, e, simultaneamente, não temos enfrentado com o devido escopo analítico - em que se pesem as iniciativas fragmentadas em nichos especializados.

Há acordo em afirmar que nada seria mais equivocado, do ponto de vista sociológico, do que tratar os expressivos episódios de rechaço classista à presença de alguns setores em aeroportos e restaurantes grã-finos como algo casual. Tampouco se pode ignorar manifestações como rolezinhos e afins, dirigidas, no bojo de uma relativa

\footnotetext{
* UFSCar - Universidade Federal de São Carlos. Departamento de Ciências Sociais. São Carlos - SP Brasil. 13565-905 - lidianesrgues@gmail.com. http://orcid.org/0000-0003-2011-9888.

** UFSCar - Universidade Federal de São Carlos. Departamento de Sociologia. São Carlos - SP - Brasil. 13565-905 - constantemartins@gmail.com. http://orcid.org/0000-0003-2700-3319.
} 
democratização dos bens de consumo, às dimensões simbólicas correspondentes aos grupos sociais abastados que tradicionalmente monopolizavam o gozo dos mesmos (GRÜN, 1996; 2003a; 2004; MESQUITA, 2012). Trata-se de manifestações que requerem análises sociológicas, na medida em que seus nexos com as transformações mais amplas da estratificação são evidentes, porém ainda não esclarecidos plenamente. Ao facultar o acesso a bens econômicos (por meio de programas como Minha casa, mina vida; Bolsa família - dentre outros) simultaneamente ao acesso a bens simbólicos (por meio de programas como Prouni; Reuni; Ciência sem Fronteiras dentre outros) (NOGUEIRA, 2000; ROMANELLI, 2000; SOUZA, 2012, 2006), as gestões presidenciais petistas engendraram um quadro sociológico do mais alto interesse - sobretudo, ainda que não exclusivamente, do ponto de vista teórico bourdiesiano (BOURDIEU, 2015; 2007; 1996).

No plano das artes e da cultura, as reviravoltas produzidas pelas mudanças morfológicas desencadeadas por políticas de redistribuição de renda são notáveis. Estas transformações se manifestaram nos padrões de gosto, consumo e busca por estilo de vida dignificado e/ou empoderado, indo das camadas mais destituídas às camadas médias e são correlatas às modificações morfológicas nos públicos das artes plásticas, do cinema, dos livros (MIRA; BERTONCELO, 2019) - e, naturalmente, da música - expressão artística que tem centralidade em nosso sistema cultural (WISNIK, 2001). Não por acaso, neste domínio, e, particularmente, no gênero rap, observam-se atiçamentos competitivos típicos da rotação de classificações injuriosas a consagradoras, pontilhados pela oposição entre os princípios de mercado e militância, resultantes da morfologia heterogênea de seus produtores, produtos e consumidores (VIEIRA, 2019).

O presente dossiê foi concebido no intuito de chamar a atenção para essas reviravoltas, e de encorajar o estabelecimento da agenda de pesquisa que elas requerem. Eis o princípio de reunião dos artigos que o compõem.

Em linhas gerais e a despeito de sua variação no tempo, as presidências petistas orientaram-se, no plano das políticas públicas, aos direitos das minorias e de grupos subrepresentados em suas manifestações artísticas e culturais - notável, sobretudo, em suas políticas de acesso ao ensino superior, em suas políticas patrimoniais e na configuração dos Ministérios da Cultura e da Educação (ALMEIDA, 2015; ALMEIDA e ERNICA, 2015; PEROSA et al. 2015). Adotando a perspectiva bourdieusiana para a análise do estado (BOURDIEU, 2015), como não indagar a respeito dos efeitos disso na centralidade da literatura brasileira no interior do sistema de produção cultural; assim como nos cânones da (assim chamada) cultura nacional? É nessa direção reflexiva que se orienta o artigo Do cânone modernista à noção 
antropológica de cultura: o conceito de cultura nas políticas culturais do governo Lula (2003-2011), contribuição de Marcela Silva de Santana e Maria Eduarda da Mota Rocha, neste dossiê. As autoras caracterizam a concepção de cultura vigente nas políticas culturais do Governo Lula. Para tanto, sugerem contrastes heurísticos com outras fases da história política nacional - notadamente, três momentos: a Era Vargas (1930-1945), a Ditadura Militar (1964-1984); e as gestões de Fernando Henrique Cardoso (1994-2001). Tendo como fio condutor a redefinição do conceito de cultura legítima, promovida na gestão de Luís Inácio Lula da Silva (2002-2009), elas abordam as disputas advindas dos interesses e concepções oriundas do Estado, da sociedade civil e do mercado. Elas constatam certo ocaso da perspectiva modernista de cultura, estribada na experimentação de linguagens, e a emergência de uma noção mais antropológica, que elege como legítima - isto é digna de financiamento e consagração -os artefatos cotidianos dos grupos histórica e economicamente destituídos de bens econômicos e carentes de reconhecimento simbólico.

Do ocaso do cânone modernista passa-se à discussão sobre as transformações nas relações de dominação em contextos de ruralidade, tendo como eixo a figura do caipira. Esta é a proposta de Metarmorfoses do simbólico no Brasil rural. As transformações do início do século XXI por meio de um personagem clássico da formação do Brasil, o capira, artigo de Suzana Kleeb e Arilson Favareto. Eles tomam como base as transformações do caipira no Brasil contemporâneo, problematizando aspectos relacionados com sua recomposição na hierarquia social, alcançando assim alterações e atualizações importantes nas estruturas tradicionais de dominação no campo. O trabalho apresenta os casos de Cunha e Bofete, municípios do interior paulista, que outrora foram investigados por clássicos das ciências sociais (Emilio Willems e Antonio Candido). Dentre outros achados, o artigo identifica como, nas últimas três décadas, a valorização de atributos classificados como amenidades rurais (ar limpo, paisagens rústicas, modos de vida portadores da tradição cultural e de relações de proximidade) se transformaram em aspectos de enaltecimento do agrário e da própria vida caipira. Este processo, por seu turno, longe de representar a emancipação do caipira ou mesmo e emergência de um novo rural, nos revela, de acordo com os autores, processos complexos e diferenciados de configurações territoriais, onde coexistem velhas formas de exploração da natureza e do trabalho, com novas modalidades de uso dos recursos naturais e de inserção dos agentes sociais.

Situando sua pesquisa em momento posterior - mas não indiferente - ao que se destacou acima, concentrado nas gestões petistas, o artigo de Renata Medeiros Paolielo, Mediação e processo de reconhecimento: subjetivações para além da produção do consenso único, aborda a problemática dos processos de reconhecimento 
e titulação de áreas remanescentes de quilombos. A autora discute a experiência social sobre o corpo e sua história, o senso prático que situa o corpo do agente no mundo e sobre o mundo. Revela como identificar-se enquanto quilombola é um processo cotidiano complexo, que depende de cada agente e dos grupos familiares, dos seus objetivos e condições econômicas e políticas, bem como da articulação com as diversas agências mediadoras atuantes nas comunidades. Com base em observação etnográfica e pesquisa documental, a autora mostra os efeitos da desaceleração dos processos de identificação, demarcação e titulação sobre os territórios quilombolas do Vale do Ribeira de Iguape, em São Paulo. Esta desaceleração adquiriu ritmo mais intenso a partir de 2016, e, no caso dos territórios em questão, traz dilemas tanto em termos de identidades mobilizadas quanto para o corpus normativo, cuja extensão de ação pode vir a retomar um questionável sobrepeso nas definições sobre identidades, diferenças, território e acesso à terra.

As aludidas reviravoltas do simbólico atingiram não apenas o campo, porém também a vida urbana e a cultura política. Na esteira das transformações aludidas, a posição do Brasil nos organismos internacionais, prioritariamente nos de orientação econômica, também se alterou e não era raro ouvir-se "é um país que se precisa conhecer". Houve certa reconfiguração do Estado, que chegou a flexibilizar e democratizar o acesso a carreiras burocráticas altamente seletivas, como as do Itamaraty. Naturalmente, muitas pesquisas ainda vão se debruçar sobre esses processos, contudo, pode-se inferir do que já está disponível, que as elites políticas foram democratizadas em seu recrutamento ao longo do período (JARDIM, 2016; CODATO, FRANZ JR., 2017; GRÜN, 2004). Não seria demasiado sugerir que as reações no interior das elites tradicionais (urbanas, rurais e financeiras) estiveram na base de alguns movimentos hodiernamente denominados antipetistas - cujas manifestações pontilham desde os meios de comunicação massificados até os círculos mais restritos dos grupos dirigentes (MARTINS, ESPINOZA, 2018; GRÜN, 2005; 2003b; CRUZ, KAYSER, CODAS, 2015). Dito de outro modo, se, desde os anos da ditadura militar, poder-se-ia apostar numa espécie de "hegemonia cultural de esquerda" (SCHWARZ, 1978; ORTIZ, 1998, 1994), a emergência de movimentos de direita, a rotinização de suportes de comunicação e difusão de mensagens políticas como a internet alteraram este quadro e exigem dos pesquisadores a coragem de enfrentá-las (RODRIGUES, 2018; MESSENBERG, 2017).

Daí a relevância dos dois artigos que tratam do jornalismo neste dossiê. Tomas Undurraga e Antonio José Pedroso, em Jornalistas da Economia e homens das finanças: fascinação, ascendência e ilusão profissional discutem as relações de proximidade e tensão, entre os jornalistas especializados em economia alguns agentes 
decisivos do campo econômico. Os autores identificam, no limite, a capacidade deste último impor princípios de hierarquização, prestígio e consagração ao campo jornalístico. Trata-se de desafio interessante para a discussão a respeito da autonomia dos campos e do risco constante de heteronomização dos mesmos (SAPIRO, 2019) em que se pese a illusio da profissão, movida pela crença de que é capaz de "mexer" com o mercado.

Finalmente, o jornalismo econômico encontra-se também no centro do artigo Os economistas-colunistas no debate sobre as reformas no Brasil, de Allana Meirelles Vieira e Aline Rodrigues Chiaramonte. Circunscrevendo a análise ao debate e às tomadas de posição de um conjunto de "economistas colunistas", atuantes na Folha de S. Paulo, n'O Estado de S. Paulo e n'O Globo, a respeito da PEC 241 e das reformas da Previdência e a Trabalhista, as autoras os identificam como portadores de projetos políticos mais amplos, estribados nas doxas inculcadas pelos espaços sociais de que são provenientes.

Compondo este número da Revista Estudos de Sociologia encontra-se também a entrevista, realizada por Maria Eduarda da Mota Rocha e Lidiane Soares Rodrigues com Sergio Miceli, a respeito dos quarenta anos de Intelectuais e classe dirigente no Brasil (1920-1945). De um modo particular, que convém explicitar, o conteúdo dela encontra-se no coração do apelo que caracteriza este dossiê. O leitor atento perceberá que as entrevistadoras se empenharam em realçar o entrelaçamento da concepção desta tese incontornável, com os dilemas políticos que se apresentavam à geração de seu autor. Há desafios similares que se apresentam à nossa, embora nossas condições materiais para fazer face a eles sejam infinitamente mais precárias. Não sabemos se estaremos à altura deles, mas a proposta deste dossiê é uma paráfrase prática do espírito de "amor sem uso", que animava as palavras, dignas de nota pois registram o espírito que irmanava a referida obra à de sociólogos da cultura (RODRIGUES, 2019), de geração anterior:

A dose de baixeza que se tornou rotina na universidade de agora e nos mídia, sem falar na degradação de profissões liberais inteiras, do ensino secundário e da administração pública, chama à revolta. Mostra o destino que está tendo o estudo entre nós, e aponta para a luta social como a única - não há nenhuma outra chance de regeneração.

Uma produção intelectual grande, importante, dispersa, desejosa de participação, e descontente da participação que lhe deram. A situação é péssima, excelente para fazer uma revista (SCHWARZ, 1981, p.19). 
Referências

ALMEIDA, A. F. M.; ERNICA, M. Inclusão e segmentação social no Ensino Superior público no Estado de São Paulo (1990-2012). Educação e Sociedade, n. 130, 2015.

ALMEIDA, W. M. Os herdeiros e os bolsistas do PROUNI na cidade de São Paulo. Educação e Sociedade, n. 130, v. 36, 2015.

BOURDIEU, P. As regras da arte. Lisboa: Editorial Presença, 1996.

A distinção: crítica social do julgamento. São Paulo/Porto Alegre:

Edusp/Zouk, 2007.

. Sobre o Estado. São Paulo: Companhia das Letras, 2015.

CODATO, Adriano; FRANZ JR. Paulo. Recrutamento ministerial no Brasil: comparando as presidências de FHC e Lula. Revista eletrônica do Programa de PósGraduação da Câmara dos Deputados, v. 10, p.44-62, 2017.

CRUZ, S. V.; KAYSER, A.; CODAS, G. (orgs). Direita, volver! O retorno da direita e o ciclo político brasileiro. São Paulo: Editora Fundação Perseu Abramo, 2015.

JARDIM, M. C. Estado e mercado no governo Lula: convergência e divergência no mercado de fundos de pensão. Agenda Política, v. V.4, p.333-362, 2016.

GRÜN, R. O Medo do Desemprego e a Mudança nos Sistemas Simbólicos da Classe Média Brasileira. In. REIS, E. et al. (eds.). Política e Cultura: Visões do Passado e Perspectivas Contemporâneas. São Paulo, Hucitec/ANPOCS, 1996.

. A Promessa da 'Inserção Profissional Instigante' da Sociedade em Rede: A Imposição de Sentido e a sua Sociologia. DADOS, vol. 46, nº 1, 2003a.

. Fundos de Pensão no Brasil do Final do Século XX: Guerra Cultural, Modelos de Capitalismo e os Destinos das Classes Médias. Mana, vol. 9, nº 2, $2003 \mathrm{~b}$.

. A Sociologia das Finanças e a Nova Geografia do Poder no Brasil. Tempo Social, v. 12, $\mathrm{n}^{\circ} 2,2004$.

A Evolução da Governança Corporativa no Brasil: Inovações Financeiras e Convergência das Elites. Revista Brasileira de Ciências Sociais, vol. 58, 2005. 
MARTINS, R; ESPINOZA, R. Colonialidade e efeitos de verdade sob a perspectiva socioambiental. Contemporânea, vol.08, n.01, 2018, p.83-109.

MESSENBERG, D. A direita que saiu do armário: a cosmovisão dos formadores de opinião dos manifestantes de direita brasileiros. Sociedade e Estado, v. 32, n. 3, p.621-648, 2017.

MESQUITA, W. Ampliação do acesso ao ensino superior privado lucrativo brasileiro: um estudo sociológico com bolsistas do Prouni na cidade de São Paulo. Tese (Doutorado em Sociologia) Faculdade de Filosofia Letras e Ciências Humanas, 2012.

MIRA, M. C. M.; BERTONCELO, E. R. E. Para além da distinção? Desafios à ordem bourdieusiana da formação social do gosto. Revista Estudos de Sociologia, v. 24, n. 46, 2019.

MICELI, S. Intelectuais e classe dirigente no Brasil (1920-1945). São Paulo: DIFEL, 1979.

NOGUEIRA, M. A. A construção da excelência escolar - Um estudo de trajetórias feito com estudantes universitários provenientes de camadas médias intelectualizadas. In: NOGUEIRA, M.; ROMANELLI, G.; ZAGO, N. (org.). Família \&

Escola: trajetórias de escolarização em camadas médias e populares. Petrópolis: Vozes, 2000.

ORTIZ, R. A moderna tradição brasileira. São Paulo: Brasiliense, 1994.

Cultura brasileira e identidade nacional. São Paulo: Brasiliense, 1998.

PEROSA, G. et. al. O espaço das desigualdades educativas em São Paulo. Proposições, v. 27, n.2, 2015.

RODRIGUES, L. S. Uma revolução conservadora dos intelectuais (Brasil/2002-2016). Política e Sociedade, v. 17, n. 39, 2018.

. As regras da subversão: Roberto Schwarz, Bertha Dunkel e a revista Teoria e Prática. Revista IEB, n. 74, p.61-80, 2019.

ROMANELLI, G. Famílias de camadas médias e escolarização superior dos filhos: o estudante-trabalhador. In: NOGUEIRA, M.; ROMANELLI, G.; ZAGO, N. (org.).

Família \& Escola: trajetórias de escolarização em camadas médias e populares. Petrópolis: Vozes, 2000. 
SAPIRO, G. Rethinking the concept of autonomy for the sociology of symbolic goods. Symbolic Goods, n. 4, 2019.

SCHWARZ, R. Cultura e Política: alguns esquemas (1964-1969)". In $\mathbf{O}$ pai de família e outros estudos. São Paulo: Paz e Terra, 1978.

. Amor sem uso. Novos Estudos Cebrap, n.1, v.1, 1981.

SOUZA, J. A construção social da sub-cidadania. Belo Horizonte/Rio de Janeiro; UFMG/Iuperj, 2006.

. Os batalhadores brasileiros: nova classe média ou nova classe trabalhadora? Belo Horizonte: UFMG, 2012.

VIEIRA, D. A nova condição do rap: entre mercado e luta antirracista. Nexo Jornal, 26 de novembro de 2019.

WISNIK, J. M. A gaia ciência: literatura e música popular no Brasil. In: Ao encontro da palavra cantada. Rio de Janeiro: 7 letras, 2001. 